\title{
Calculation of the Levelised Cost of Electrical Energy Storage for Short-Duration Application. LCOS Sensitivity Analysis
}

\author{
Vikenty Melnikov ${ }^{1}, *$ Gleb Nesterenko ${ }^{1}$, Anton Potapenko ${ }^{2}$ and Dmitry Lebedev ${ }^{2}$ \\ ${ }^{1}$ Novosibirsk State Technical University, Novosibirsk 630073, Russian Federation \\ ${ }^{2}$ Energy Storage Systems LLC, Novosibirsk 630007, Russian Federation, www.estorsys.com
}

\section{Abstract}

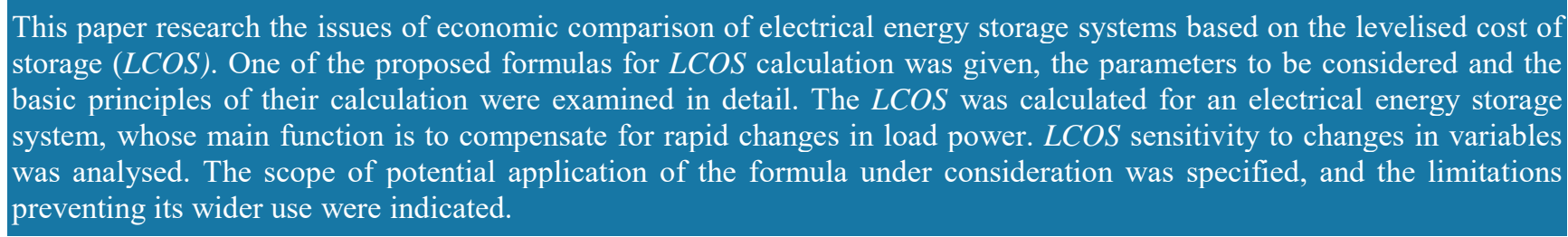

Keywords: electrical energy storage systems, LCOS, storage units, distributed generation, gas engine power plant, microgrids, renewable energy sources.

Received on 25 May 2018, accepted on 07 July 2018, published on 02 October 2018

Copyright (C) 2018 Vikenty Melnikov et al., licensed to EAI. This is an open access article distributed under the terms of the Creative Commons Attribution licence (http://creativecommons.org/licenses/by/3.0/), which permits unlimited use, distribution and reproduction in any medium so long as the original work is properly cited.

doi: 10.4108/eai.13-7-2018.155643

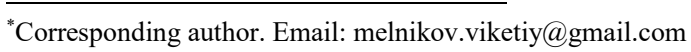

\section{Introduction}

The growing global interest in small-scale and distributed generation, as well as the use of renewable energy sources, results in a high demand for electrical energy storage systems (ESS), which use various storage devices: electrochemical storages (which are primarily addressed in this paper), supercapacitors, gravity batteries etc. Nevertheless, as of today, there is no generally accepted economic indicator which would allow us to compare different energy storage systems, unlike in the planning of construction of power plants, for example, where the indicator "Levelised Cost of Electricity (LCOE)" has been accepted. Modification of the formula for $L C O E$ calculation $[1,2]$, having adapted it for electrical energy storage systems, was proposed. The indicator derived in this way was called "Levelised Cost of Storage (LCOS)". Despite the fact that currently there is no LCOS calculation procedure approved by international and national standards, this indicator is actively used by manufacturers, analytical agencies [3], government bodies [4], and other persons working in the field of energy storage.

\section{Methodology}

In general, the levelised cost of storage shows the intrinsic value of a $\mathrm{kWh}$ of energy delivered by an ESS, for which it should be sold to achieve a zero net present value (NPV). The LCOS is determined as the sum of all investments over the lifetime of an ESS divided by the cumulative energy generated as a result of these investments.

The authors of this paper have calculated the LCOS of an ESS for use in the power supply system of a self-contained industrial facility characterised by an abruptly variable load 
pattern using the following formula, as modified in comparison with [1]:

$$
L C O S=\frac{\text { Capital }+\sum \frac{\left(O \& M_{t}(1+i)^{t}+F u e l_{t}(1+e)^{t}\right)}{(1+r)^{t}}}{\sum \frac{M W h_{t}(1+e)^{t}}{(1+r)^{t}}} .
$$

$\begin{array}{ll}\begin{array}{l}\text { Where: } \\ \text { Capital } \\ \text { O\&\&M }\end{array} & \begin{array}{l}\text { total capital costs; } \\ \text { operating and maintenance costs } \\ \text { over time } t ;\end{array} \\ \text { the cost of electricity stored over } & \text { time } t ;\end{array}$

Unlike the base formula [1], the proposed variant considers inflation and annual tariff growth.

\subsection{Capital costs}

In general, capital costs include the following types of costs: design work, land allocation, the cost of the plant, transportation to the site, installation, start-up and commissioning activities. That is, these are the costs included in the cost of the electrical energy storage system, or the costs incurred directly by the customer.

There are different approaches to the calculation of capital costs: the company's own funds or borrowed funds may be used, the costs may be distributed by years according to work stages (design, construction, pilot operation) etc. In this case, the LCOS was calculated based on the condition that the customer's own funds were used; all capital costs were carried to the first year of project implementation.

\subsection{Operating costs}

Electrochemical energy storage systems contain no rotating parts, which is why they are low-maintenance systems and characterised by low operating costs (less than $1 \%$ of the cost annually). The necessary routine maintenance activities include periodic control discharge of the storage units (once a year for the case under consideration, the periodicity depending on the ESS usage rate) to determine the residual energy storage capacity of the system. The control discharge can be performed remotely or automatically if this is provided for by the design and functional capabilities of the control subsystem.

In addition to the maintenance costs, LCOS calculations should also consider the expenses for buying electricity to supply power to the control and communications subsystem, as well as the auxiliary subsystem, which includes airconditioning, heating, ventilation, fire-extinguishing systems etc. This is particularly important taking into consideration the fact that the amount of electrical energy consumed by the auxiliary subsystems can be significant, which is caused by the need to maintain a microclimate inside the engineering envelope (container or prefabricated modular building) required for normal operation of ESS equipment.

\subsection{Stored energy cost}

This parameter reflects the costs incurred for charging the storage unit. It should be noted that these costs cannot always be estimated at the design stage, for example, when an ESS operates in conjunction with generator sets using conventional fuel in the frequency maintenance mode, compensation for rapid changes in load power, and other short-duration applications, i.e., when Class A ESS are used according to the classification [9].

\subsection{Amount of delivered electricity}

The amount of electricity delivered or stored by an ESS (taking efficiency into account) over time $t$. The calculation is typically performed throughout the ESS lifetime, but other options are also possible depending on external conditions. At the design stage, the amount of electricity delivered over its lifetime can be calculated based on the service life of the storage unit, determined by the number of complete chargedischarge cycles, or based on the estimated lifetime of the ESS considering its operation mode, for example, operating as a backup power supply.

\section{LCOS calculation}

The power supply system of a self-contained industrial facility, for which the LCOS was calculated, uses a gas engine power plant as the main source of electricity. The electrical energy storage system is designed to compensate for load power shedding and surges inadmissible for gas engine generators. Table 1 shows the input data necessary for LCOS calculation.

The base prices shown in Table 1 were used to calculate the value of the levelised cost of energy storage. According to the formula (1), LCOS equal to $0.53 \$ / \mathrm{kWh}$ was obtained.

\section{Sensitivity analysis}

LCOS sensitivity to changes in the following variables was assessed: capital costs, operating costs, cost of electricity, amount of electricity, discount rates, and electricity tariff growth rates. The parameters may change due to both changes in external factors, and because of errors in calculations or assumptions at the design stage.

As shown in Figure 1, LCOS is the most sensitive to changes in such parameters as capital costs (this is since the 
cost of equipment constitutes $90 \%$ of all costs) and total energy delivered over the lifetime.

Table 1. Input data for the LCOS calculation

\begin{tabular}{|c|c|c|c|}
\hline No. & Indicator & $\begin{array}{c}\text { Unit of } \\
\text { measure }\end{array}$ & Value \\
\hline 1 & Design life & years & 12 \\
\hline 2 & $\begin{array}{l}\text { Energy storage capacity to } \\
\text { power ratio }\end{array}$ & $\mathrm{kWh} / \mathrm{kW}$ & 0.3 \\
\hline 3 & Discount rate & $\%$ & 8 \\
\hline 4 & Capital costs, Cap & $\$$ & 750000 \\
\hline 4.1 & Cost of equipment & $\$$ & 700000 \\
\hline 4.2 & $\begin{array}{l}\text { Installation, start-up and } \\
\text { commissioning }\end{array}$ & $\$$ & 45000 \\
\hline 4.3 & Transportation & $\$$ & 5000 \\
\hline 5 & Operating costs & $\$ /$ year & 11700 \\
\hline 5.1 & Maintenance and repair & $\$$ /year & 3200 \\
\hline 5.2 & $\begin{array}{l}\text { Buying electricity for } \\
\text { auxiliaries }\end{array}$ & $\$$ /year & 8500 \\
\hline 6 & $\begin{array}{l}\text { Electricity delivered over the } \\
\text { lifetime }\end{array}$ & MWh & 1500 \\
\hline 6.1 & Cycles per day & units & 1.28 \\
\hline 6.2 & ESS efficiency & $\%$ & 94 \\
\hline
\end{tabular}

It should be noted that analytical agencies calculate the total exchange energy based on the condition that a unit performs 1 complete charge-discharge cycle within one day, but this approach cannot be universal. For electrical energy storage systems, a great number of various application scenarios are possible, which directly affect the amount of energy delivered (MWh parameter). For example, when an ESS performs the power backup function, it may not perform one complete charge-discharge cycle within one day or even one month. In which case its lifetime will be limited not by the number of cycles, but by natural battery degradation (the typical lifetime claimed by manufacturers is 15 to 20 years). Therefore, when consumers compare different storage technologies being guided solely by the LCOS value, they will prefer a storage device with a greater number of charge-discharge cycles, although for the backup application, the ability of an ESS to operate in the boost charge mode (float charge mode) for a long time is of primary importance.

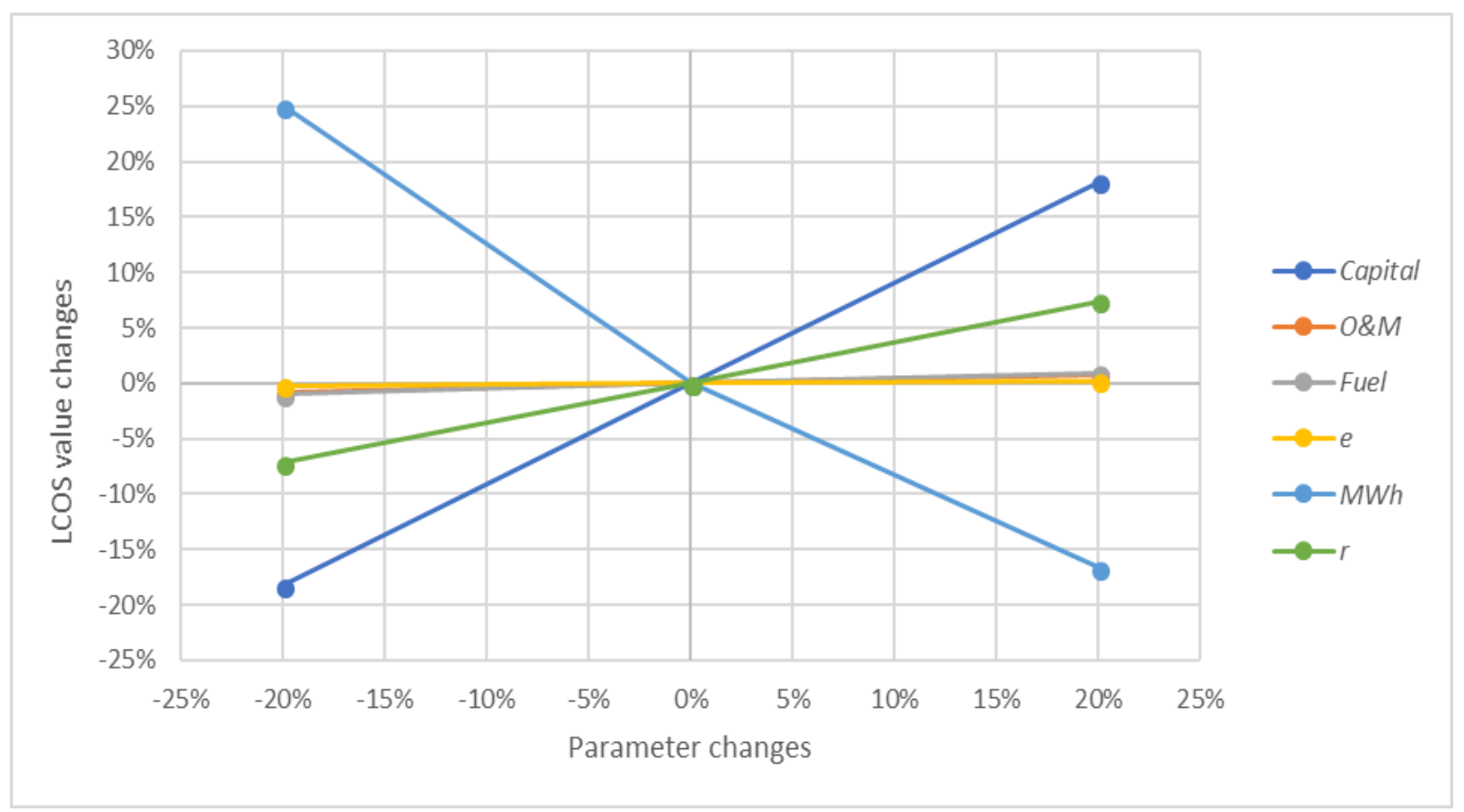

Figure 2. Sensitivity analyse for short-term ESS

\section{Conclusion}

According to the calculation results obtained based on the above calculation procedure, the levelised cost of storage for the examined case of using an ESS in a self-contained power system is $0.53 \$ / \mathrm{kWh}$.

The purpose of using the LCOS is to calculate the unit cost of the electrical energy stored and delivered over the 
ESS lifetime. This indicator does not consider the economic benefits provided by additional functional capabilities: reactive power compensation, improved quality of electrical energy etc.

The conducted analysis of LCOS sensitivity to changes in the initial parameters has shown that the value of this indicator is mainly affected by two parameters: the capital cost of the system and the amount of energy delivered. It should be noted that the capital cost of storage can be determined quite accurately using the manufacturers data. At the same time, as a rule, the amount of energy delivered by an ESS cannot be determined very accurately at the design stage, because ESS operation is exposed to both external (such as climatic) and internal (changes in power consumption, disconnection of generating units) factors.

The formula (1) used to calculate the LCOS is a convenient indicator for comparing different electrical energy storage systems with similar functions and technical parameters. It should be specified that for two identical systems operating at different facilities, the LCOS will not generally be the same, which is related to the specific features of the facilities where the ESS is installed, the functions performed by the ESS, and the external climatic factors. Therefore, to adequately assess the economic feasibility of using an electrical energy storage system, currently, the most reliable results can be provided by a detailed feasibility study. At the same time, the authors of this paper believe that it is necessary to develop and approve a uniform LCOS calculation procedure considering the specifics of ESS assignment to obtain a transparent mechanism for comparing competitive offers, because currently every manufacturer makes their own assumptions in calculations, which makes proper comparison of the options under consideration impossible.

\section{References}

[1] Lai. C., McCulloch, M. (2017) Levelized Cost of Energy for PV and Grid Scale Energy Storage Systems. Systems and Controls, 1, 1-1.

[2] Manasseh O., Jensen, S., Ferris, J., Bass, R. (2017) Calculation of levelised costs of electricity for various electrical energy storage systems. Renewable and Sustainable Energy Reviews, 67, 908-920.

[3] Lazard's Levelised Cost of Storage Analysis - Version 3.0, LAZARD, 2017.

[4] The concept of development of the market of electricity storage systems in the Russian Federation. Ministry of Energy of the Russian Federation, 2017(in Russian).

[5] Belderbos, A., Delarue, E., Kessels, K., D'haeseleer, W., (2017) Levelised cost of storage - Introducing novel metrics, Energy Economics, 67, 287-299.

[6] Lotfi, H., Majzoobi, A., Khodaei A., Bahramirad, S., Paaso, E. (2016) Levelised Cost of Energy Calculation for Energy Storage Systems, 2016 Grid of the Future Symposium, Paris, October 2016.

[7] Pawel, I. (2013) The cost of storage - how to calculate the levelised cost of stored energy (LCOE) and applications to renewable energy generation. 8th International Renewable Energy Storage Conference and Exhibition, IRES 2013

[8] Electrical energy storage (EES) systems - Part 1: Vocabulary, International standard IEC 62933-1., year, p.

[9] Electrical energy storage (EES) systems - Part 2-1: Unit parameters and testing methods - General specification. International standard IEC 62933-2-1. year, $p$.

[10] Electrical Energy Storage (EES) systems - Part 3-1: Planning and installation - General specifications. Draft International standard IEC 62933-3-1 (draft). year, p.

[11] V.D. Melnikov, A.M. Potapenko Energy storage systems in the power supply systems of industrial enterprises//Industrial efficiency in the age of smart manufacturing, 2017, No. 8, p. 43 (in Russian) 